\title{
POTENTIAL DISTRIBUTION OF HAWTHORN IN NEW ZEALAND
}

\author{
J.M. KEAN \\ AgResearch, Private Bag 4749, Christchurch, New Zealand \\ Corresponding author: john.kean@agresearch.co.nz
}

\begin{abstract}
Hawthorn (Crataegus monogyna), a bird-dispersed, introduced shrub, is becoming increasingly weedy in parts of New Zealand, North America, Australia and elsewhere. In order to identify areas threatened by this species, an eco-climatic model for its potential global distribution was constructed using CLIMEX software. The model was based on the native range of hawthorn in Europe and validated against the invaded range elsewhere in the world. It suggests that hawthorn could potentially invade most lowland and montane areas of New Zealand. In lowland areas, invasion is likely to be limited by grazing pressure, but changes in the management of South Island montane grasslands as a result of the current tenure review process may favour hawthorn invasion in some areas. Pre-emptive action to identify and remove infestations from montane grasslands is recommended. Keywords: Crataegus monogyna, invasion, distribution, CLIMEX.
\end{abstract}

\section{INTRODUCTION}

Hawthorn, Crataegus monogyna Jasc., is a bird-dispersed woody weed native to Europe, western Asia and the northern coast of Africa. It has long been associated with human activity, with numerous references in folklore and having been used medicinally since Roman times. Hawthorn accompanied European emigrants around the world, primarily for use in hedging, and has become an invasive weed in several areas, such as North America and Australia (Bass et al. 2006). It is also of international concern as a host of fireblight (Vanneste 2000). In New Zealand, hawthorn is targeted in the current pest management strategies of four of the sixteen Regional Councils (Auckland, Gisborne, Canterbury and Southland), and is actively managed for fireblight control in Hawke's Bay and Tasman-Nelson. It is also recognised by the Department of Conservation as a threat to some native environments. A detailed study at Porters Pass has quantified the invasion of hawthorn into semi-modified montane grassland (Williams \& Buxton 1996), and recent work suggests that its spread accelerated in the 1960s as a result of land use changes that encourage blackbirds, its primary dispersal agent in New Zealand (P.A. Williams, Landcare Research, unpubl. data).

The current paper uses CLIMEX software (Sutherst et al. 1999) to predict the potential distribution of hawthorn globally, and in New Zealand in particular. CLIMEX facilitates the development of an empirical eco-climatic suitability model, based on the geographic distribution and basic eco-physiological knowledge (e.g. threshold climate tolerances) of a species. CLIMEX has been widely used for informing risk assessment and management of weeds (e.g. Kriticos et al. 2004) and invasive insects (e.g. Kriticos et al. 2007).

\section{METHODS}

The worldwide native and invaded distribution of hawthorn was compiled, including synonyms but excluding known hybrids. A primary source of occurrence data was the Global Biodiversity Information Facility (GBIF 2009), which listed >100,000 geo-referenced data points for hawthorn, $98 \%$ of which lay within the British Isles, The Netherlands, France, Germany and Spain. In order to visualise this large dataset, latitudes and longitudes were averaged for points lying within $1^{\circ} \operatorname{arc}$. This consolidated 
dense occurrence data without affecting the sparser outliers that are critical for model fitting. These data were complemented with a further 833 occurences derived from other internet databases together with published books and journal papers, actively targetting geographical areas outside the core distribution suggested by the GBIF data. New Zealand hawthorn occurrences were obtained from the Department of Conservation BioWeb database $(n=622)$, GBIF $(n=63)$, the Landcare Research NZFlora database $(n=5)$, regional pest management strategies $(n=6)$, and the South Island farmer survey reported by Bascand \& Jowett $(1982)(\mathrm{n}=56)$. The precision of all occurrence data was assessed, and only records with a precision of less than a few kilometers were used. The data were validated within the constraints of information availability, concentrating on outliers and recently invaded countries.

A CLIMEX model (Sutherst \& Maywald 1985; Sutherst et al. 1999; Kriticos et al. 2004) was fitted to the native distribution of hawthorn using climate data with 10' arc resolution (New et al. 2002). The model was then validated against distribution data for the rest of the world, excluding New Zealand. Finally, the model was used to predict the potential hawthorn distribution in New Zealand using the $5 \mathrm{~km}$ resolution Virtual Climate Station (VCS) data grid (Tait et al. 2006).

\section{RESULTS AND DISCUSSION}

The fitted CLIMEX model (Table 1) suggested broad environmental tolerances to be able to capture the native distribution of hawthorn (Fig. 1). The southern part of its distribution in North Africa, southern Turkey and central Spain was determined by the heat stress parameters. Northern limits were determined by cold stress (to fit Finland and Russia) together with relatively high upper bounds for soil moisture tolerance (to fit western Norway). Hawthorn is known to be particularly tolerant of both flooding (Vreugdenhil et al. 2006) and drought (Hinckley et al. 1980), so it was not surprising that additional wet and dry stress parameters were found to add little to the model fit and could be omitted.

TABLE 1: CLIMEX parameters fitted to the native distribution of hawthorn.

\begin{tabular}{llccc}
\hline Limiting factor & Parameter & Symbol & Value & Unit $^{1}$ \\
\hline Temperature & lower threshold & DV0 & 6 & ${ }^{\circ} \mathrm{C}$ \\
& lower optimum temperature & DV1 & 18 & ${ }^{\circ} \mathrm{C}$ \\
& upper optimum temperature & DV2 & 26 & ${ }^{\circ} \mathrm{C}$ \\
& upper threshold & DV3 & 30 & ${ }^{\circ} \mathrm{C}$ \\
\multirow{4}{*}{ Moisture } & annual degree-day requirement & PDD & 600 & ${ }^{\circ}$ day \\
& lower soil moisture threshold & SM0 & 0.1 & \\
& lower optimum soil moisture & SM1 & 0.4 & \\
& upper optimum soil moisture & SM2 & 1.0 & \\
Cold Stress & upper soil moisture threshold & SM3 & 2.5 & \\
& temperature threshold & TTCS & 3 & ${ }^{\circ} \mathrm{C}$ \\
Heat Stress & stress accumulation rate & THCS & -0.00015 & week $^{-1}$ \\
& temperature threshold & TTHS & 35 & ${ }^{\circ} \mathrm{C}$ \\
& stress accumulation rate & THHS & 0.005 & week $^{-1}$ \\
\hline
\end{tabular}

${ }^{1}$ Values without units are dimensionless indices. 


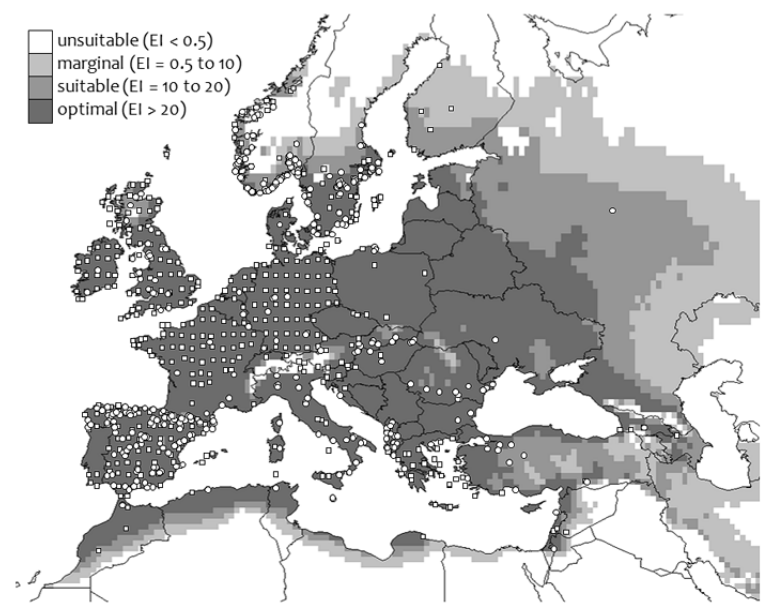

FIGURE 1: CLIMEX eco-climatic index (EI) fitted to the native distribution of hawthorn (squares = GBIF data, circles = other occurrence data).

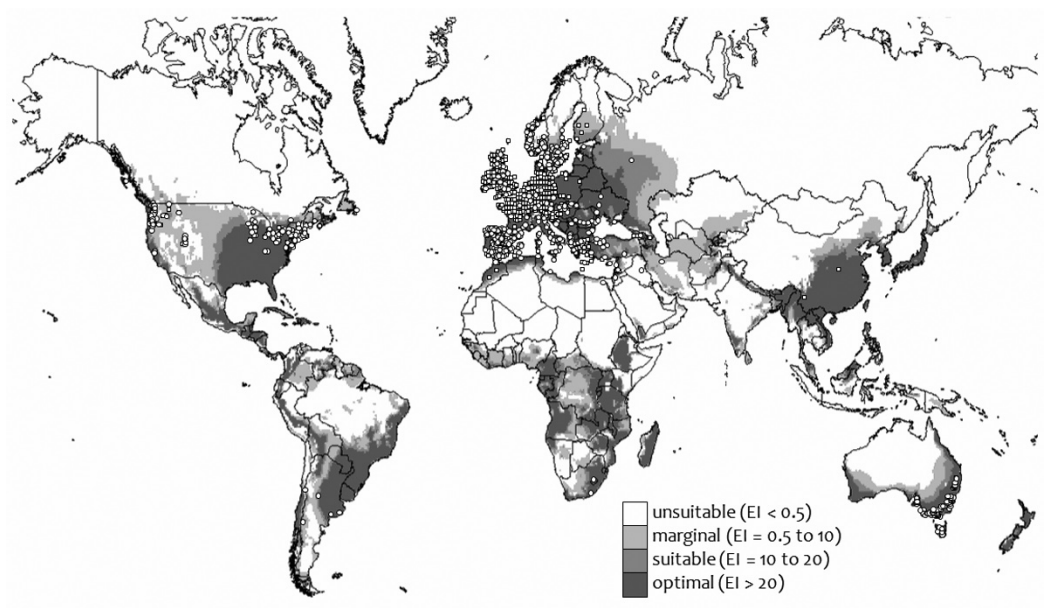

FIGURE 2: Predicted global potential distribution of hawthorn (squares = GBIF data, circles $=$ other occurrence data).

Hawthorn occurrences worldwide (Fig. 2) including native and non-native distributions lay within the predicted potential range. Apparently isolated records from North America (Utah, Queen Charlotte Islands, Alaska and Newfoundland) correspond to small local areas predicted to be suitable for hawthorn, lending confidence to the validity of the model. The few data available for Asia, southern Africa and South America, also lie within areas predicted to be suitable. The predicted range in Australia was substantially larger than the area from which occurences have been reported. Given the relatively high number of occurrences reported from Australia, this suggests a possible flaw in the fitted model. 
However, efforts to match a modified model to the Australian distribution compromised the fit in northern Africa, and adding an additional hot-wet stress that is unlikely to occur in the native range improved the fit only along the Queensland coastline.

This leaves three main possibilities. First, hawthorn may not yet have realised its full potential range in Australia, as implied by Bass et al. (2006). Secondly, the empirical CLIMEX model may fail to consider some specific ecological drivers, such as competition with other vegetation, which exclude hawthorn from otherwise suitable areas. Finally, Australian hawthorn populations may represent a subset of native genotypes with a narrower eco-climatic range than is suggested by models fitted to the native distribution. Each of these factors is likely to occur to some degree in all invasive populations, so that CLIMEX models will tend to overestimate the suitable geographic range for invasive species.

The predicted potential distribution of hawthorn in New Zealand (Fig. 3) encompasses virtually all lowland and montane areas. This is not surprising, given that hawthorn is abundant throughout the entire British Isles, and the similarity of New Zealand's climate to Britain has been demonstrated by Peacock \& Worner (2006). This prediction is supported by the distribution of hawthorn records in New Zealand. However, there remain some large areas of apparently suitable land for which there are no or few current records.

In the case of Fiordland, the apparent absence of hawthorn probably reflects its inability to invade dense native forests, although one record from the Manapouri pylon road suggests the role of human disturbance in facilitating spread into such remote areas. The lack of records from Stewart Island may indicate that hawthorn has not been introduced there. Similarly, hawthorn may not be present in much of Taranaki, East Cape, the Mackenzie Basin and Central Otago, or these areas may simply have been poorly sampled.

The relative dearth of seed dispersers in New Zealand (P.A. Williams, Landcare Research, pers. comm.) suggests that natural spread of hawthorn will probably never achieve the rapid spread reported from Australia (Bass et al. 2006). Much of the largescale dispersal of hawthorn within New Zealand was almost certainly due to its early use as a hedging species. Hawthorn hedges are still very common in some parts of the country, although in some fruit-growing areas they have been largely removed due to their ability to harbour fireblight (Vanneste 2000). Natural spread from hedges is probably minimal in pastoral areas with heavy grazing, but Bascand \& Jowett (1982) found hawthorn was becoming weedy in the more lightly grazed pastures of dry South Island areas. Williams \& Buxton (1986) showed that hawthorn can successfully invade montane grasslands, and it may be here that it is of greatest concern. Historically, most of the South Island's montane grasslands have been crown-owned and under long-term lease to high-country farmers. However, the current tenure review process is leading to substantial changes in the ownership and administration of these areas, many of which may be potentially invaded by hawthorn (Fig. 3). At Porters Pass, hawthorn spread apparently originated from a planting next to an abandoned dwelling, and recent work suggests a sixfold increase in its rate of increase there from about 1960, coinciding with local land use changes that lowered grazing pressure and favoured blackbirds, the primary vector for hawthorn spread in New Zealand (P.A. Williams, Landcare Research, unpubl. data). Similar changes arising from the current tenure reviews are likely to facilitate hawthorn spread in many montane South Island areas, suggesting that land managers should consider pre-emptive action to prevent future impacts such as those currently occurring at Porters Pass (Williams \& Buxton 1986). Since there are currently few recorded populations in these areas (Fig. 3), recommended action would include a survey for hawthorn presence, focussing initially on abandoned homestead sites, and removal of hawthorn hedgerows and isolated plants from susceptible areas. 

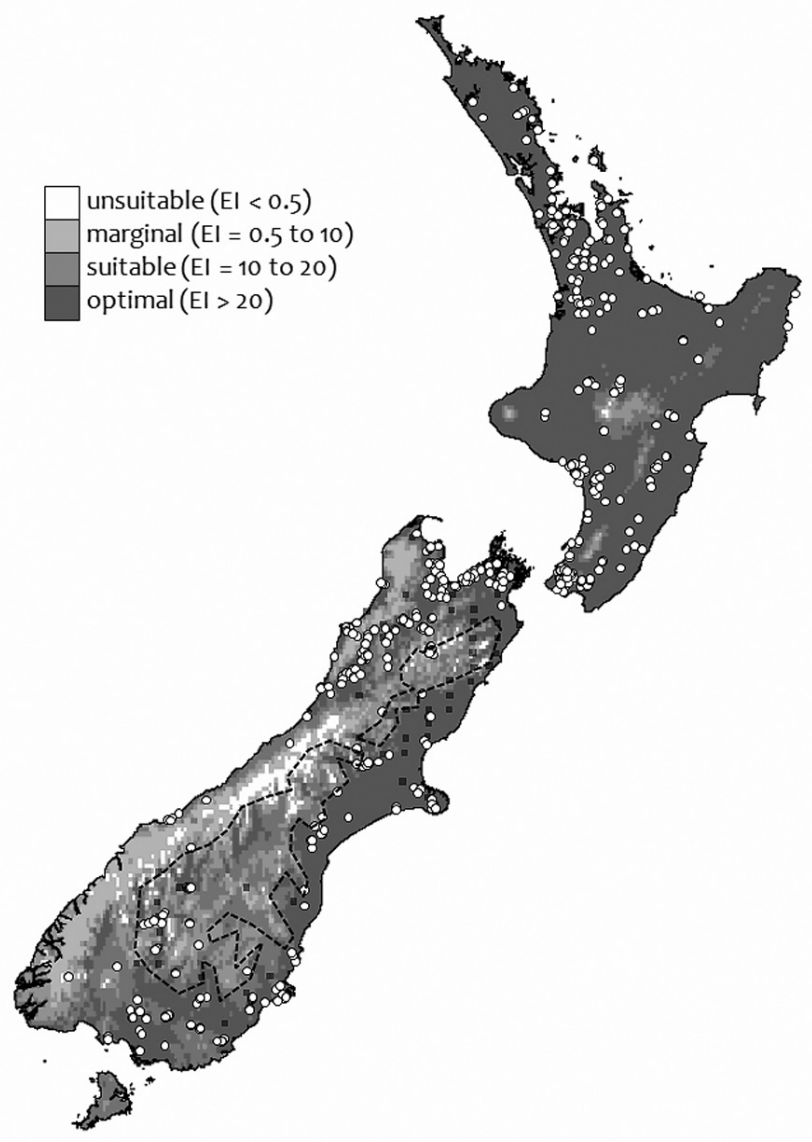

FIGURE 3: Predicted potential distribution of hawthorn in New Zealand compared to recorded occurrences (dark squares = approximate locations recorded by Bascand \& Jowett (1982), circles = other occurrence data). Dotted lines delimit areas of predominantly crown pastoral lands.

\section{ACKNOWLEDGEMENTS}

I am grateful to Clayson Howell and Lesley Henderson for help obtaining occurrence records, to Gunter Maywald, Darren Kriticos and Cor Vink for assistance with model fitting, and to Graeme Bourdôt, Shona Lamoureaux, Ian Popay, Sue Zydenbos and an anonymous referee for helpful suggestions on the manuscript. This work was funded by the Foundation for Research, Science and Technology through the Beating Weeds programme, Contract C09X0504. 


\section{REFERENCES}

Bascand LD, Jowett GH 1982. Scrubweed cover of South Island agricultural and pastoral land 2: Plant distribution and managerial problem status. New Zealand Journal of Experimental Agriculture 10: 455-492.

Bass DA, Crossman ND, Lawrie SL, Lethbridge MR 2006. The importance of population growth, seed dispersal and habitat suitability in determining plant invasiveness. Euphytica 148: 97-109.

GBIF 2009. Global Biodiversity Information Facility. http://www.gbif.org (accessed 4 May 2009).

Hinckley TM, Duhme F, Hinckley AR, Richter H 1980. Water relations of drought hardy shrubs: osmotic potential and stomatal reactivity. Plant, Cell and Environment 3: 131-140.

Kriticos DJ, Lamoureaux S, Bourdôt GW, Pettit W 2004. Nassella tussock: current and potential distributions in New Zealand. New Zealand Plant Protection 57: 81-88.

Kriticos DJ, Stephens AEA, Leriche A 2007. Effect of climate change on oriental fruit fly in New Zealand and the Pacific. New Zealand Plant Protection 60: 271-278.

New M, Lister D, Hulme M, Makin I 2002. A high-resolution data set of surface climate over global land areas. Climate Research 21: 1-25.

Peacock L, Worner SP 2006. Using analogous climates and global insect distribution data to identify potential sources of new invasive insect pests in New Zealand. New Zealand Journal of Zoology 33: 141-145.

Sutherst RW, Maywald GF 1985. A computerised system for matching climates in ecology. Agriculture, Ecosystems and Environment 13: 281-299.

Sutherst RW, Maywald GF, Yonow T, Stevens PM 1999. CLIMEX: Predicting the effects of climate on plants and animals. User Guide. CSIRO Publishing, Melbourne, Australia.

Tait A, Henderson R, Turner R, Zheng X 2006. Thin plate smoothing spline interpolation of daily rainfall for New Zealand using a climatological rainfall surface. International Journal of Climatology 26: 2097-2115.

Vanneste JL 2000. Fire Blight: The Disease And Its Causative Agent, Erwinia amylovora. CABI Publishing, CABI International Wallingford, UK. 370 p.

Vreugdenhil SJ, Kramer K, Pelsma T 2006. Effects of flooding duration, frequency and depth on the presence of saplings of six woody species in north-west Europe. Forest Ecology and Management 236: 47-55.

Williams PA, Buxton RP 1986. Hawthorn (Crataegus monogyna) populations in midCanterbury. New Zealand Journal of Ecology 9: 11-17. 